\title{
Cannabinoid hyperemesis syndrome with extreme hydrophilia
}

\author{
This article was published in the following Dove Press journal: \\ International Journal of General Medicine \\ 16 August 2013 \\ Number of times this article has been viewed
}

\author{
Hilary A Enuh' \\ Julia Chin' \\ Jay Nfonoyim² \\ 'Department of Medicine, ${ }^{2}$ Critical \\ Care Unit, Richmond University \\ Medical Center, Staten Island, \\ NY, USA
}

\begin{abstract}
Marijuana is the most widely used recreational drug in the US. Hyperemetic hydrophilic syndrome is a previously described but infrequently recognized condition of cannabinoid abuse with hyperemesis and obsessive hot showering. We present a 47-year-old male known marijuana addict with intractable abdominal pain who could not wait for physical examination, meal, or medication, because of obsessive compulsive warm baths. He had a history of epilepsy and addiction to marijuana, which he took on the day of admission. He presented to the hospital with a seizure, complicated by nausea, vomiting, and severe abdominal pain. His examination was unremarkable, except for mild epigastric tenderness. His laboratory and radiological tests were within normal limits, except for a positive urine drug screen for marijuana and opiates. He took himself immediately to the bathroom and remained under a hot shower with the exception of two 15-minute breaks for the rest of the day. He stated that it made him feel better than medication. Receiving medication and even eating was a problem because of this compulsive showering. Abstinence from marijuana during the hospital stay made the patient's nausea and vomiting resolve significantly. Cannabinoid hyperemesis is a differential diagnosis among patients with intractable nausea, vomiting, and obsessive hot bathing. The syndrome is an unmistakable indication of marijuana addiction. A thorough history and observation is very valuable. Recognition of this entity will reduce unnecessary testing and utilization of health care resources.
\end{abstract}

Keywords: cannabinoid, compulsive bathing, cyclic vomiting, hyperemesis, hydrophilia, marijuana

\section{Introduction}

Marijuana is the most widely used recreational drug in the US and worldwide. ${ }^{1}$ Cannabinoid hyperemesis is a syndrome characterized by severe nausea and hyperemesis associated with chronic marijuana abuse and marked by compulsive bathing habits, which temporarily alleviate symptoms. ${ }^{2}$ This hyperemetic hydrophilic syndrome is a previously described but infrequently recognized condition. We present a 47-year-old male marijuana addict with intractable abdominal pain, who could not wait for physical examination, meal, or medication because of obsessive compulsive hot showering.

\section{Case report}

A 47-year-old African American male with a history of epilepsy and drug addiction presented to the hospital with a seizure complicated by nausea, vomiting, and severe abdominal pain. He was known to be diabetic, hypertensive, and addicted to marijuana for 30 years. He smoked two to three "blunts" (cigar hollowed out and filled
Department of Medicine, Richmond University Medical Center, 355 Bard Avenue, Staten Island, NY 103I0, USA Email enuh2010@yahoo.com 
with marijuana) most days and occasionally up to eight blunts daily. The drug was last taken on the day of his admission.

His examination was unremarkable except for heart rate of $92 \mathrm{bpm}$, blood pressure of 174/98 $\mathrm{mmHg}$, and mild epigastric tenderness. His laboratory and radiological tests were within normal limits, except for blood sugar of $217 \mathrm{mg} / \mathrm{dL}$ and positive urine drug screen for marijuana and opiates. The patient refused electroencephalography.

He immediately went to the bathroom and remained under a hot shower with the exception of two 15-minute breaks for the rest of the day. He believed that a warm shower could relieve his nausea and vomiting. He stated that it made him feel better than medication. Intravenous ondansetron was of limited benefit. It was difficult to persuade him to exit the shower for the rounds and physical examination. Receiving medication and eating were problems because of this compulsive showering. The same event of entrenching himself in the shower had happened 2 months prior to his hospitalization for a grand mal seizure. Abstinence from marijuana during the hospital stay made the patient's nausea, vomiting, and obsessive warm showering resolve after 3 days. He was discharged after 4 seizure-free days and referred for drug rehabilitation.

\section{Discussion}

Obsessive-compulsive disorder is an anxiety disorder characterized by uncontrollable, unwanted thoughts and repetitive, ritualized behaviors frequently manifested by obsessive hand-washing. ${ }^{3,4}$ However, hyperemetic hydrophilic syndrome is not an anxiety disorder. Chronic marijuana use can lead to cannabinoid hyperemesis with a compulsive need to shower. Cannabinoids are being medically used for the treatment of nausea, vomiting, glaucoma, anorexia, and anxiety, ${ }^{5}$ especially among patients receiving chemotherapy. The mechanism of action in inhibiting nausea and vomiting is not precisely known, but it may be related to stimulation of the cannabinoid receptors in the brain.

Paradoxically, chronic use of marijuana can cause intractable abdominal pain, nausea, and emesis, the cause of which often goes unrecognized. The condition was first described by Allen et al in 2004 as cannabinoid hyperemesis syndrome. ${ }^{6}$ The most intriguing component of the syndrome is the compulsive showering in hot water to relieve the symptoms. Insufficient acknowledgment of this new syndrome has led to unnecessary testing and utilization of health care resources in diagnosing recurrent abdominal pain and vomiting among some patients.

Cannabinoids act mainly through two receptors: cannabinoid receptor type $1\left(\mathrm{CB}_{1}\right)$ and $\mathrm{CB}_{2}$ in the brain. ${ }^{7,8}$
$\mathrm{CB}_{1}$ is present in the brain and gut. The paradoxical association between chronic cannabinoid use and cyclic vomiting has not been extensively studied. Chronic marijuana use stimulates $\mathrm{CB}_{1}$, which results in decreased peristalsis. ${ }^{9}$ Proposed mechanisms include prolonged cannabinoid halflife caused by fat solubility, delayed gastric emptying, and thermoregulatory disturbances via the limbic system. ${ }^{6} \mathrm{CB}_{1}$ receptors exert their neuromodulatory role in the central nervous system and the enteric plexus. Tetrahydrocannabinol (THC) acts on $\mathrm{CB}_{1}$ receptors in the brain, which are also present in the gut. ${ }^{6}$ Chronic stimulation with this lipophilic compound may produce toxicity in sensitive patients. ${ }^{10}$ It is known that $\mathrm{CB}_{1}$ stimulation by cannabinoids slows gastric emptying and peristalsis, but the mechanism of this action is not clear and may be mediated by both the brain and gut, with gut activity overriding brain $\mathrm{CB}_{1}$ activity in chronic users of THC. ${ }^{11}$ Hyperemetic hydrophilia may be attributed to complication of long-term use. These symptoms may resolve in 24-48 hours with conservative management and cessation of marijuana use. ${ }^{9}$ Our patient exhibited a similar outcome.

Compulsive warm showering behavior is a strong feature of cannabinoid hyperemesis. It occurs in about $91 \%$ of cases. ${ }^{12}$ Some patients have reported having more than 20 lengthy baths in a day, while others spent 3-6 hours in the bathroom and applied hot water bottles to the abdomen to relieve symptoms. ${ }^{13}$ Our patient preferred wearing only a towel around his waist so that he did not spend any time removing the hospital gown to shower once the urge came. One patient reported, "I ran out of hot water at home, and I used a shower in an adjacent hospital room when the hot water in this room ran out." ${ }^{10}$ The actual mechanism on how hot baths relieve symptoms of cannabinoid hyperemesis is unclear. However, it is thought that because $\mathrm{CB}_{1}$ is close to the thermoregulatory center of the hypothalamus, chronic $\mathrm{CB}_{1}$ hypothalamic stimulation might be counteracted by warm bathing. ${ }^{2}$ Patterson et al theorized that $\mathrm{CB}_{1}$-mediated vasodilation of the gut with chronic cannabinoid use may contribute to the symptoms, thus a temporary relief of symptoms may be related to a redistribution of blood flow from the gut to the skin with warm bathing. ${ }^{2}$

\section{Conclusion}

Cannabinoid hyperemesis should be considered a differential diagnosis among patients with intractable nausea, vomiting, and obsessive hot bathing. Hyperemetic hydrophilia syndrome is an unmistakable indication of marijuana addiction. A thorough history and observation is very 
valuable. Recognition of this entity will reduce unnecessary testing and utilization of health care resources.

\section{Acknowledgment}

We are grateful to Professor Dennis Bloomfield, MD for reviewing this article. Written informed consent was obtained from the patient for publication of this case report.

\section{Disclosure}

The authors report no conflicts of interest in this work.

\section{References}

1. Leggett T. A review of the world cannabis situation. Bull Narc. 2006;58(1-2):1-155.

2. Patterson D, Smith E, Monahan M, et al. Cannabinoid hyperemesis and compulsive bathing: a case series and paradoxical pathophysiological explanation. J Am Board Fam Med. 2010;23(6):790-793.

3. Mayo Clinic. Obsessive-compulsive disorder (OCD): definition. 2010. Available from: http://www.mayoclinic.com/health/ obsessive-compulsive-disorder/DS00189. Accessed June 29, 2013.

4. Wikipedia. Obsessive-compulsive disorder. 2013. Available from http:// en.wikipedia.org/wiki/Obsessive $\%$ E2\% $\% 0 \% 93$ compulsive_disorder. Accessed July 1, 2013.
5. Sontineni, Chaudhary S, Sontineni V, Lanspa S. Cannabinoid hyperemesis syndrome: clinical diagnosis of an under recognised manifestation of chronic cannabis abuse. World J Gastroenterol. 2009;15(10): 1264-1263.

6. Allen JH, De Moore GM, Heddle R, Twartz JC. Cannabinoid hyperemesis: cyclical hyperemesis in association with chronic cannabis abuse. Gut. 2004;53(11):1566-1570.

7. Croxford JL. Therapeutic potential of cannabinoids in CNS disease. CNS Drugs. 2003;17(3):179-202.

8. González S, Cebeira M, Fernández-Ruiz J. Cannabinoid tolerance and dependence: a review of studies in laboratory animals. Pharmacol Biochem Behav. 2005;81(2):300-308.

9. Darmani NA, Crim JL. Delta-9-tetrahydrocannabinol differentially suppresses emesis versus enhanced locomotor activity produced by chemically diverse dopamine D2/D3 receptor agonists in the least shrew (Cryptotis parva). Pharmacol Biochem Behav. 2005;80(1):35-44.

10. Chang YH, Windish DM. Cannabinoid hyperemesis relieved by compulsive bathing. Mayo Clin Proc. 2009;84(1):76-78.

11. Izzo AA, Camilleri M. Emerging role of cannabinoids in gastrointestinal and liver diseases: basic and clinical aspects. Gut. 2008;57(8): $1140-1155$.

12. Simonetto D, Oxentenko A, Herman M, Szostek J. Cannabinoid hyperemesis: a case series of 98 patients. Mayo Clin Proc. 2012;87(2): 114-119.

13. Wallace E, Andrews S, Garmany C, Jelley M. Cannabinoid hyperemesis syndrome: literature review and proposed diagnosis and treatment algorithm. South Med J. 2011;104(9):659-664.
International Journal of General Medicine

\section{Publish your work in this journal}

The International Journal of General Medicine is an international, peer-reviewed open-access journal that focuses on general and internal medicine, pathogenesis, epidemiology, diagnosis, monitoring and treatment protocols. The journal is characterized by the rapid reporting of reviews, original research and clinical studies across all disease areas.

\section{Dovepress}

A key focus is the elucidation of disease processes and management protocols resulting in improved outcomes for the patient. The manuscript management system is completely online and includes a very quick and fair peer-review system. Visit http://www.dovepress.com/ testimonials.php to read real quotes from published authors. 